\title{
A brief Analysis on the Optimization Measures of Safety Management in Coal Mine Construction
}

\author{
Xiyang Feng
}

Yunnan Land and Resources Vocational College; Kunming 650217 China

\begin{abstract}
There are many unsafe factors in the construction of coal mine, so it belongs to the high-risk industry. Therefore, it is necessary to refine the safety management of coal mine construction, and create a safe and stable production environment to reduce the occurrence of personal injury incidents. Safety management is the basis of reducing safety accidents, and the optimization measures should be taken for the defects in safety management.
\end{abstract}

Key words: Construction of coal mine; Safety management; Management optimization.

\section{INTRODUCTION}

There are many risk factors in the construction of coal mine. If there are defects in the safety management work, it is easy to cause the safety accident, causing the damage of the construction personnel and the loss of the construction equipment. In order to effectively reduce the coal mine safety accident in construction, it requires to analyze the characteristics of coal mine safety management and then adopt optimization measures to eliminate the potential safety hazard existing in the coal mine construction and promote the development of security and stability of coal mining enterprises.

\section{CHARACTERISTICS OF COAL MINE CONSTRUCTION}

There are certain risks in the process of coal mine construction, involving various safety risks. There are many unfavorable factors in coal mine construction, such as poor operation conditions, prone to landslides and gas. In the process of construction, affected by the geological conditions in the area, three dimensional cross constructions exist in the construction work surface, and the mechanical equipment usually adopts large equipment. As many kinds of support materials are needed in the construction, and the construction site will change frequently. If there is negligence in the safety management of the coal mine construction process, safety accidents are very easy to happen.

Because of the large risks in the construction of coal mines, they are listed in high-risk industries. It is easy to cause personal injury accidents and property losses, and affect the economic benefits of enterprises, if the safety management is not strengthened in coal mine construction. Therefore, it is necessary to optimize the safety management of coal mine construction and ensure safe construction.

Safety management is an important part of coal mine enterprise management. Only by ensuring the safe construction can the safety accident be reduced and the whole construction process be safe. The safety production law of our country also clarified the coal mine construction, which requires the coal mine enterprises to attach great importance and strengthen the management of the construction process so as to realize the safe production. 


\title{
FACTORS AFFECTING THE SAFETY OF COAL MINE CONSTRUCTION
}

\author{
Subjective Factors
}

People are important factors related to security. Coal mine construction is inseparable from human participation and safety management and stable operation of equipment needs human maintenance. In order to ensure the safe construction of coal mines, we should pay attention to the management of human beings and give play to the initiative and enthusiasm of people in safety management. Therefore, the safety management of coal mines should focus on improving people's safety awareness and enhancing people's safety skills. Create conditions for coal mine safety by strengthening the safety management towards people. Safety management is comprehensive and systematic, so the management is difficult. Human factors can affect construction safety, and human unsafe behavior can lead to safety accidents. Therefore, there should be someone responsible for coal mine safety, and the personnel responsible for safety management must have comprehensive quality.Not only should we be familiar with the production of coal mine, but also master the operation condition of the construction equipment and the method of safety management. We should have certain technical skills, and the ability of safety strain and safety management. Only in this way, can the safety of construction be ensured. During the construction period, the standardized operation of construction personnel is the basic condition for ensuring safe production. However, some construction workers do not pay attention to safety, lack of safety awareness, and attach importance to production but neglect safety. In addition, people are prone to slack in the construction process, and are insensitive to the existing safety risks, which can easily lead to safety accidents.

\section{Objective Factors}

In the coal mining, the stable operation of construction equipment is necessary to guarantee the safe production. If there is no effective management for ventilation equipment, the stability of the equipment will be affected and the construction equipment will not guarantee the normal function and there will be potential hazard. Therefore, in order to ensure the safety of coal mine, it is necessary to have a supporting equipment management system, and equipment management is the foundation for the safety of coal mine. For instance, the management effect of ventilation equipment is directly related with ventilation safety.

A sound safety management system is also an important condition for ensuring safety. If there is no a sound safety management system in coal mine production, safety concerns are much harder to eliminate. And all kinds of safety inspection systems are difficult to implement, not according to the standard to make the necessary repair maintenance. So the reliability of equipment operation and the coal mine safety are difficult to be guaranteed.

The geological structure of some coal mines is complex, and unfavorable geological conditions will have an impact on the construction of coal mines. The geological structure of the mining area will have a significant impact on the safety of coal mines, because the coal mines are mostly in remote mountainous areas, coal mining is mostly underground mining.

In coal mining, with the deepening of mining, the gas concentration will continue to increase, as well as the temperature. If the ventilation conditions of the mine cannot be guaranteed, it is easy to cause a safety accident. In addition, if the coal seam temperature rises to a certain extent, it will cause combustion after contacting with oxygen. The space of the mine is relatively small and the air flow is poor. If it cannot be ventilated in time, there is a danger of explosion and cause safety accidents, so the mine ventilation is especially important.

Because coal mining is more special, the geographical position is more complex. And the function of the equipment will be flawed and the reliability of the equipment will be hard to be ensured if the design personnel don't pay enough attention to equipment management or don't have professional abilities. There will also exist some potential safety hazard if the operation is not stable.

\section{PRINCIPLES OF SAFETY MANAGEMENT OPTIMIZATION}

\section{Closed-loop Management}

The safety management of coal mines needs a perfect management system, and we must pay attention to the prevention of accidents to realize the risk control of life safety. Accident prevention will transform post processing into prior control, which could change the passive response into active preventive measures, achieving the forward 
movement of safety management. To achieve this effect, we need to adopt closed loop management, and define the objects, responsibilities, processes, standards and measures of safety management. Safety management should form a long-term management mechanism, which needs to adopt circular mode to manage according to the principle of PDCA, so as to ensure the closed loop management of safety. This management mode adopts continuous circulation rising, as the coal mine safety management adopts dynamic type. It can realize the coordination between people, machines, things, law and ring, changing the original manage source.

\section{Risk Pre-Control}

In view of the safety risk factors of coal mine, we should adopt the management mode of risk prevention. The safety management should increase the pre-control ability and identify the various risk factors in the coal mine construction. Risk identification should be regarded as the hazard factors existing in the whole process of coal mine construction, including people's behavior, physical state of thing and management existence of loopholes. Management goal can be more clear through risk identification. And unsafe factors can be divided into diversified classes through risk assessment to ensure the key point of safety management and it should be clearly controlled.

\section{Continuous Improvement}

The key to safety management of coal mine construction is the implementation of pre-control. Therefore, it is necessary to carry out an accurate assessment with the hazard sources in the construction site and to establish the corresponding hazard control system and countermeasures on this basis. Adopt the way of control for hazards in advance to cut off the dangerous conditions that may occur. In addition, hazard sources should be dynamically monitored to analyze the problems found in the supervision process and take corrective measures. Meanwhile, the new hazard source is required to be identified in order to provide the basis for the safety risk management in the next step and realize the pre-control of danger, which can continuously improve the safety management.

\section{OPTIMIZATION MEASURES OF SAFETY MANAGEMENT}

\section{Optimization of Safety Management System}

Coal mining enterprises optimize the existing safety management system through combining the reality. In the management of coal mine, construction work is the most important management content, and the safety management of coal mine construction directly reflects how to correctly handle the relationship between "man" and "thing". In order to ensure the management effect of the "thing", safety inspection is needed to eliminate the hidden danger; while the management of "man" includes management of construction personnel and safety management.

Before the construction work, the construction personnel should be given the work instruction to make it clear the specific contents of the construction, including the construction order, construction methods, standards, personnel coordination, safety hazards, risk prevention measures and so on; before the implementation of the operation, the relevant construction personnel should be arranged to be familiar with the construction site, and further verify the various aspects of safety measures. In view of the difficulty of construction work, potential safety hazards, possible safety accidents and easy negligent links in construction, combined with the existing safety management system and typical cases, safety education for construction personnel is carried out to raise workers' consciousness of compliance with safety rules and regulations. Personnel are deeply aware of the importance of implementing safety measures to ensure safe construction.

Safety is related with human behaviors. In the construction work, if the mind is relaxed, the work procedure may be simplified in construction, and there will be illegal phenomena, which can lead to safety accidents. So coal enterprises should pay attention to improving the construction personnel safety consciousness and skills, and construction personnel should have the ability to identify safety risk factors of working sites to have the ability to cope with sudden accidents.

The coal mine enterprise should pay attention to the safety of investment, and the safety protective equipment of the construction personnel on the site should ensure the standard quality, and complete specifications. The construction personnel of education shall correctly wear and use safety protective equipment and use reliable safety protective equipments to meet the needs of safety construction. Those protective equipments that have lost performance are strictly prohibited to use. 
In order to enhance the construction of coal mine safety management, safety management personnel should have the thought of "safety first" and consciousness to fully realize the importance of coal mine safety management. The hidden danger should be timely discovered and handled, and the fluky psychology cannot exist.

Safety management personnel should pay attention to improving their own qualities, actively learn and master the laws and regulations related to safety management and rules and regulations. The coal mining enterprises should focus on promoting the safety management system and ensure the standardization of safety management through using the system to regulate safety. Scientific and reasonable safety management system is a vital foundation for reducing safety accidents. The safety management personnel should focus on the analysis of the hazards existing in the construction work and take corresponding safety precautions according to the analysis results. Safety management personnel should attach more importance to check the reliability of safety equipments and the working status of the construction personnel in the coal mine construction to ensure that the safety measures can be in place. Illegal operations and risky behaviors should be resolutely stopped.

\section{Management of Strengthening Construction Site}

Safety risk is an unavoidable problem in production process, especially for coal mine construction. In view of the hidden danger existing in coal mine operation, various measures should be taken to eliminate and deal with it to the maximum extent. The focus of safety management is to adopt preventive measures. Only by actively managing hidden dangers can the situation of passive handling of accidents be effectively eliminated. Therefore, the management of coal mine construction site should be strengthened and the ability of prevention should be improved.

Coal mining enterprises should pay attention to raising the overall level of construction equipment so as to enhance the safety and reliability in the construction process. Coal mine safety management should be combined with technology management to play a role in ensuring safety. For example, popularizing and using output monitoring system can make construction in an orderly state. With the help of gas monitoring system, the gas condition of construction site can be dynamically grasped, and the safety of underground construction personnel can be ensured.

Coal mine enterprises should arouse more consciousness of safety management and technical upgrading of construction equipment. A sound management system should exist to ensure the reliability of construction equipment. The equipment of coal mine construction should be strictly designed and installed according to the relevant standards, and the involved enterprises should inspect and maintain the construction equipment regularly.

The safety management measures of construction site are the basis of safety. The disorderly placement of construction site materials and the lack of safety measures will not only affect the normal operation, but also increase the possibility of personal injury.

The management of coal mine construction site should focus on the management of key parts and links, the comprehensive treatment of the construction site, and the improvement of the safety standard of coal mine construction site. It is necessary to strengthen the underground water disaster control. Construction under the condition of no wind or breeze should be prohibited; to prohibit construction when gas overruns occur, and to monitor closely the change of gas in the construction site; and to pay close attention to the situation of the driving surface. The tunneling surface should be well ventilated, and the drainage is smooth; the construction equipment should be standardized to operate, the equipment that has hidden dangers should be strictly prohibited; to prevent the explosion caused by incorrect operation of the electrical apparatus; in respect of underground construction, the initiating explosive devices should be strictly managed according to the system, the personnel involved in the explosion should have professional quality under professional training, and the blasting should be strictly carried out according to the relevant operating standards. The transportation and storage of industrial products should have safety management measures; in addition, the comprehensive control of gas should be focused, the monitoring should be real-time, the extraction should be guaranteed, the ventilation be reliable and the management measures should be in place.

\section{CONCLUSION}

There are many unsafe factors in coal mine construction. The safety management of coal mine is an important subject to ensure the safety of coal mine. It is necessary to optimize safety management for coal mine construction, which is the basis to ensure safety management of coal mine. For the production of coal mine, it is necessary to establish long-term mechanism of safety management to continuously reduce coal safety accidents. 


\section{REFERENCES}

1. Wei Li. A brief discussion on the development of coal mine safety management[J]. Modern Economic Information,2016(11).

2. Weijun Yang. Discussion on problems and countermeasures existing in coal mine safety management[J]. Safety and Health,2016(7).

3. Jicheng Guo. Thoughts on coal mine safety management work[J]. Coal mine safety,2017(1).

4. Lixin Ni. Discussion on the "three elements" of safety culture construction in coal mine[J]. Chinese Coal,2016(3).

5. Bo Li and Dianchen Wang. Research and practice on precautionary management of coal mine safety warning[J]. Chinese Coal,2016(12).

6. Yajun $\mathrm{Xu}$. The enlightenment of safety production management of coal mine in developed countries[J]. Coal Technology,2016(9). 